\title{
BMJ Open Effect of cardiologist care on 6-month outcomes in patients discharged with heart failure: results from an observational study based on administrative data
}

\author{
Vera Maria Avaldi, ${ }^{1}$ Jacopo Lenzi, ${ }^{1}$ Stefano Urbinati, ${ }^{2}$ Dario Molinazzi, ${ }^{3}$ \\ Carlo Descovich, ${ }_{4}^{4}$ Anselmo Campagna, ${ }^{5}$ Martina Taglioni, ${ }^{6}$ Angelo Fioritti, ${ }^{7}$ \\ Maria Pia Fantini ${ }^{1}$
}

To cite: Avaldi VM, Lenzi J, Urbinati S, et al. Effect of cardiologist care on 6-month outcomes in patients discharged with heart failure: results from an observational study based on administrative data. BMJ Open 2017;7:e018243. doi:10.1136/ bmjopen-2017-018243

- Prepublication history and additional material for this paper are available online. To view these files, please visit the journal online (http://dx.doi. org/10.1136/bmjopen-2017018243).

Received 14 June 2017

Revised 8 September 2017

Accepted 29 September 2017

CrossMark

For numbered affiliations see end of article.

Correspondence to

Dr Jacopo Lenzi;

jacopo.lenzi2@unibo.it

\section{ABSTRACT}

Objectives To evaluate the effect of cardiologist care on adherence to evidence-based secondary prevention medications, mortality and readmission within 6 months of discharge in patients with heart failure (HF).

Design Retrospective observational study based on administrative data.

Setting Local Healthcare Authority (LHA) of Bologna, one of the largest LHAs of Italy with $\sim 870000$ inhabitants. Participants All patients residing in the LHA of Bologna discharged from hospital with a diagnosis of HF between 1 January 2015 and 31 December 2015.

\section{Primary and secondary outcome}

measures Multivariable regression analysis was used to assess the association of inpatient and outpatient cardiologist care with adherence to evidence-based medications, all-cause mortality and hospital readmission (including emergency room visits) within 6 months of discharge.

Results The study population included 2650 patients (mean age 82.3 years). 340 (12.8\%) patients were discharged from cardiology wards, while 635 (24.0\%) were seen by a cardiologist during follow-up. Inpatient and outpatient cardiologist care was associated with an increased likelihood of adherence to ACE inhibitors/ angiotensin receptor blockers (ACEls/ARBs), $\beta$-blockers and aldosterone antagonists after discharge. The risk of mortality was significantly lower among patients adherent to ACEIs/ARBs and/or $\beta$-blockers ( $-53 \%$ and $-28 \%$, respectively); the risk of hospital readmission was significantly lower among patients adherent to ACEls/ARBs $(-28 \%)$.

Conclusions Compared with non-specialist care, cardiologist care improves patient adherence to evidencebased medications and might thus favourably affect mortality and readmission following HF.

\section{INTRODUCTION}

Heart failure (HF) is a complex clinical syndrome with a prevalence ranging from $1 \%$ to $3 \%$ in the adult population of high-income
Strengths and limitations of this study

- This is one of the first studies in Italy to investigate the effect of inpatient and outpatient cardiologist care on process (medication adherence) and outcome measures (mortality and readmission) in patients with heart failure.

- Healthcare use of each individual patient was mapped through the linkage of different administrative data sources using the patient's unique identifier.

- Administrative databases do not include lifestyle behaviours and some relevant clinical information that may affect the study outcomes.

countries and whose prevalence increases up to $30 \%$ among people older than 85 years of age. ${ }^{12} \mathrm{HF}$ is a major public health issue due to population ageing, the complex management of elderly patients and the recurrent hospital admissions, which account for most of HF-related costs. ${ }^{3}$

Evidence about the role of cardiologists in the management of $\mathrm{HF}$ is controversial. Research studies have, to date, compared cardiologist care with care provided by generalists or other physicians in relation to mortality and readmissions. ${ }^{4-18}$ Most of them suggested that patients with HF have improved outcomes when seen by a cardiologist $^{4-11}$; on the other hand, other authors did not find outcome differences between cardiologist and non-cardiologist care, ${ }^{12-14}$ while Lowe et $a l^{15}$ reported that patients managed by cardiologists have a higher mortality rate. Interestingly, a few other studies have highlighted the beneficial effect of the collaboration between generalists and cardiologists in improving processes and outcomes for these patients. ${ }^{16-18}$ Also, some authors found 
that patients treated by cardiologists, compared with those treated by generalists or other physicians, are more frequently male, younger, ${ }^{4681013}$ and receive more evidence-based drug prescriptions and invasive procedures. ${ }^{6-8} 10{ }^{11}$ In light of this consideration, it has been suggested that cardiologist care could be associated with higher costs and resource use. ${ }^{4}$

Still, given the small number of studies on this topic and the high heterogeneity between them in terms of design and setting, with less studies evaluating outpatient cardiologist care, comparison groups and outcomes time frame, there is still no consistent evidence that cardiologist care should be preferred in the management of HF. To date, patients with HF are predominantly treated by non-cardiologists to respond to organisational rather than clinical demands; nevertheless, it is essential to ascertain the benefits of specialty care to improve HF management, both in terms of effectiveness and efficiency. This entails the implementation of a structured model of care that involves cardiologists, beyond generalists and other physicians.

The aim of this study was to evaluate the effect of both inpatient and outpatient cardiologist care on adherence to evidence-based secondary prevention medications, all-cause mortality and readmission within 6 months of discharge after HF in the Local Healthcare Authority (LHA) of Bologna, one of the largest LHAs of Italy.

\section{MATERIALS AND METHODS \\ Setting and study population}

This retrospective observational study included all patients residing in the LHA of Bologna (866 000 inhabitants in 2015) who were discharged from hospital with a primary diagnosis of HF International Classification of Diseases, Clinical Modification (ICD-9-CM) diagnosis codes: 398.91, 402.x1, 404.x1, 404.x3, 428.xx) between 1 January 2015 and 31 December 2015. Data were retrieved from the Hospital Discharge Records (HDRs) Database (see online supplementary file 1 for a description of the data source).

Patients were excluded if any of the following criteria were met:

1. age $>100$ years, because very old patients may have distinctive clinical features at diagnosis and survival

2. a secondary diagnosis of non-cardiogenic acute pulmonary oedema (ICD-9-CM 518.4), that is, patients with symptoms probably related to causes other than $\mathrm{HF}$

3. a major procedure on the cardiovascular system (ICD-9-CM 00.5x, 00.66, 35.xx, 36.xx, 37.3x-37.8x, 37.94-37.99), that is, patients with severe cardiac impairment

4. length of stay $>90$ days, that is, very complex or unstable cases

5. planned hospital admission, to focus analyses on acute/urgent episodes of care
6. transfer from another facility, to ascribe the study outcomes to the hospital of first admission

7. death during hospital stay or discharge against medical advice.

For patients with multiple eligible hospital admissions over the 1-year study period, we considered only the first one as the index admission.

\section{Cardiologist care}

The independent variables of interest were related to inpatient and outpatient cardiologist care. These included the following:

1. type of ward of discharge (cardiology, internal medicine, geriatrics, other)

2. outpatient cardiology visit during follow-up.

We also took into account in the analyses some care processes implemented in the LHA of Bologna for the elderly and patients with HF. In particular, we considered the following:

1. Continuing home care (not necessarily focused on HF) delivered by general practitioners (GPs) or nurses, before index hospitalisation or during followup.

2. Inclusion in a specific HF care pathway before index hospitalisation or during follow-up. Since 2008 the LHA of Bologna has implemented this care pathway for the integrated management of patients with HF. GPs meet to share evidence-based guidelines and to manage along with skilled nurses the patient's follow-up, and fast tracks are activated for diagnostic tests when needed. Patients can be referred by GPs or by hospital specialists when the diagnosis is made for the first time during hospitalisation. The HF care pathway promotes patient self-management through counselling by nurses to improve lifestyle and optimise therapy compliance, detection of early acute symptoms of HF, and an easier access to specialist and non-specialist care when needed.

3. Access to residential care facility for the elderly (RCFE) before index hospitalisation or during followup.

Information on outpatient care was collected from regional and LHA administrative databases, and linked to HDRs using the patient's unique identifier.

\section{Study outcomes}

The study had three outcomes of interest. Specifically:

1. Adherence to evidence-based secondary prevention medications, consisting of three drug categories: ACE inhibitors/angiotensin receptor blockers (ACEIs/ ARBs), $\beta$-blockers and aldosterone antagonists. Adherence to each of the three drug classes was calculated using the medication possession ratio (MPR) on the basis of the minimum effective doses defined in clinical trials. Patients were classified a priori into two categories: adherent (MPR $\geq 75 \%$ ) and nonadherent (MPR $<75 \%$ ) (see online supplementary file 2 for the list of drugs and doses, including references 
to clinical trials). Data on filled prescriptions were retrieved from the Outpatient Pharmaceutical Database (OPD) (see online supplementary file 1 for a description of the data sources).

2. All-cause mortality, retrieved from the Regional Mortality Register Database (see online supplementary file 1 for a description of the data sources).

3. All-cause unplanned readmissions occurred at any hospital and lasting $>1$ day, including emergency room (ER) visits not related to injuries and not resulting in inpatient admission. These data were retrieved from the HDRs and ER administrative databases.

For the medication adherence analysis, we excluded patients with individual follow-up $<90$ days to give all individuals the chance to achieve clinical stability and to guarantee a minimum observation period of 3 months, and patients who spent more than $30 \%$ of their follow-up in the hospital, because drugs dispensed to inpatients cannot be retrieved from the OPD, possibly leading to immeasurable time bias. ${ }^{19}$ In the mortality and readmission analyses, medication adherence was considered as a potential predictor of the study outcome.

Repeated admissions within 2 days of discharge were regarded as one single 'episode of care' and were not counted as readmissions. The beginning of the follow-up was set at the date of hospital discharge, and all patients were followed up to 6 months.

\section{Statistical analysis}

Continuous variables were summarised as mean $\pm \mathrm{SD}$ or as median and range; discrete and categorical variables were summarised as frequencies and percentages.

In order to minimise the potential confounding of individual risk factors on the association between predictors and outcomes, we retrieved some patient baseline characteristics from HDRs. These included age, gender, citizenship, district of residence, length of stay, hospital of discharge, provision of intensive care during hospital stay, 28 comorbidities chosen a priori and identified in the index hospitalisation and in all hospital admissions occurring 2 years prior to the index hospitalisation, and use of 10 drug therapies during the 3 months prior to the index admission (see online supplementary file 3 for the detailed list of comorbidities and drugs).

The crude association between each potential confounder and the study outcomes was first examined in univariable regression models. Predictors with prevalence $>1 \%$ and significantly associated with the outcome at $\mathrm{p}<0.25$ in univariable analyses were selected for inclusion in multivariable regression models. A bootstrap procedure was used to determine which of these factors were significantly associated with the outcome in multivariable models. Using this approach, 200 replicated bootstrap samples were selected from the original cohort. In each replicated sample, a backward elimination of potential confounders was applied with a significance level of removal equal to 0.01 . Only risk factors selected in at least $50 \%$ of the replicates were included as covariates in the final regression models. The confounders included in the final models are reported in table footnotes.

The effect of healthcare factors (cardiologist care and other outpatient care services) on medication adherence was analysed using multivariable logistic regression. The effect of healthcare factors and medication adherence on the risk of mortality and readmission was analysed using multivariable conditional logistic regression (see online supplementary file 4 for methodological details).

The significance level was set at 0.01 . All analyses were carried out using Stata V.13 software.

\section{Sensitive data management}

In Italy, anonymous administrative data-gathering is subject to the law Protection of individuals and other subjects with regard to the processing of personal data, ACT no. 675 of 31.12.1996 (amended by Legislative Decree no. 123 of 09.05.1997, no. 255 of 28.07.1997, no. 135 of 08.05.1998, no. 171 of 13.05 .1998 , no. 389 of 6.11 .1998 , no. 51 of 26.02.1999, no. 135 of 11.05 .1999 , no. 281 of 30.07.1999, no. 282 of 30.07 .1999 and no. 467 of 28.12.2001) (http:// www.privacy.it/legge675encoord.html).

Data were anonymised prior to the analysis at the regional statistical office, and each patient was assigned a unique identifier that eliminates the ability to trace the patient's identity or other sensitive data. As anonymised administrative data are used routinely for healthcare management, no specific written informed consent was needed to use the patient information.

All procedures performed in this study were in accordance with the 1964 Helsinki Declaration and its later amendments.

\section{RESULTS}

Of the 3320 patients discharged after HF, 2650 (79.8\%) met the inclusion criteria. The mean age was $82.3 \pm 10.1$ years, $56.3 \%$ were women and the median length of stay was 7 days. The distribution of patient baseline characteristics is reported in table 1 .

As shown in table 1,340 (12.8\%) patientswere discharged from cardiology wards, while 1813 (68.4\%), 372 (14.0\%) and $125(4.7 \%)$ patients were discharged from internal medicine, geriatrics and other-discipline wards, respectively. There were $635(24.0 \%)$ patients seen by a cardiologist during follow-up, with a median wait time between referral and specialist appointment of 7 days. In addition, we found 1279 (48.3\%) patients with home care; of these, $836(65.4 \%)$ were already receiving this service before index admission. The most common reason for home care, as reported in the home-based service records, was administration of anticoagulants $(24.9 \%)$, followed by management of HF, coronary artery disease or dementia $(18.7 \%)$. A total of 232 patients $(8.8 \%)$ had been included in the HF care pathway; of these, 156 were included during the 6-month follow-up period. One hundred and ninety-one patients $(7.2 \%)$ were in residential care 


\begin{tabular}{|c|c|c|}
\hline Patient characteristics & $\mathrm{n}=\mathbf{2 6 5 0}$ & $\%$ \\
\hline Female & 1491 & 56.3 \\
\hline Age in years, mean $\pm S D$ & $82.3 \pm 10.1$ & - \\
\hline Foreigners & 40 & 1.5 \\
\hline Length of stay in days, median (range) & $7(1-69)$ & - \\
\hline $\begin{array}{l}\text { Provision of intensive care during } \\
\text { hospital stay }\end{array}$ & 103 & 3.9 \\
\hline \multicolumn{3}{|l|}{ Discipline of the ward of discharge } \\
\hline Internal medicine & 1813 & 68.4 \\
\hline Cardiology & 340 & 12.8 \\
\hline Geriatrics & 372 & 14.0 \\
\hline Other & 125 & 4.7 \\
\hline \multicolumn{3}{|l|}{ Comorbidities } \\
\hline Malignant tumours & 151 & 5.7 \\
\hline Diabetes & 336 & 12.7 \\
\hline Disorders of lipid metabolism & 89 & 3.4 \\
\hline Obesity & 68 & 2.6 \\
\hline Haematological diseases & 396 & 14.9 \\
\hline Arterial hypertension & 652 & 24.6 \\
\hline Previous myocardial infarction & 331 & 12.5 \\
\hline $\begin{array}{l}\text { Other forms of ischaemic heart } \\
\text { disease }\end{array}$ & 706 & 26.6 \\
\hline $\begin{array}{l}\text { III-defined descriptions and } \\
\text { complications of ischaemic heart } \\
\text { disease }\end{array}$ & 38 & 1.4 \\
\hline Rheumatic heart disease & 166 & 6.3 \\
\hline Cardiomyopathies & 198 & 7.5 \\
\hline Endocarditis and acute myocarditis & 1 & 0.04 \\
\hline Other cardiac diseases & 218 & 8.2 \\
\hline $\begin{array}{l}\text { Conduction disorders and cardiac } \\
\text { dysrhythmias }\end{array}$ & 1366 & 51.5 \\
\hline Cerebrovascular diseases & 291 & 11.0 \\
\hline Vascular diseases & 150 & 5.7 \\
\hline HIV/AIDS & 0 & 0.0 \\
\hline COPD & 339 & 12.8 \\
\hline $\begin{array}{l}\text { Pneumoconiosis and other alveolar or } \\
\text { parietoalveolar lung diseases }\end{array}$ & 17 & 0.6 \\
\hline Chronic nephropathies & 524 & 19.8 \\
\hline $\begin{array}{l}\text { Chronic diseases of liver, pancreas } \\
\text { and intestine }\end{array}$ & 47 & 1.8 \\
\hline Alcohol abuse & 0 & 0.0 \\
\hline Previous bypass surgery & 51 & 1.9 \\
\hline Previous PCl & 152 & 5.7 \\
\hline Cerebrovascular revascularisation & 20 & 0.8 \\
\hline Other surgery of the heart & 106 & 4.0 \\
\hline Other surgery of great vessels & 72 & 2.7 \\
\hline Previous HF & 736 & 27.8 \\
\hline
\end{tabular}

Continued

\section{Table 1 Continued}

\begin{tabular}{|c|c|c|}
\hline Patient characteristics & $\mathrm{n}=\mathbf{2 6 5 0}$ & $\%$ \\
\hline \multicolumn{3}{|l|}{ Number of comorbidities } \\
\hline 0 & 366 & 13.8 \\
\hline 1 & 623 & 23.5 \\
\hline$\geq 2$ & 1661 & 62.7 \\
\hline \multicolumn{3}{|l|}{ Previous medication use } \\
\hline Antidiabetic drugs & 596 & 22.5 \\
\hline Drugs for cardiac therapy & 588 & 22.2 \\
\hline Drugs for obstructive air way diseases & 602 & 22.7 \\
\hline Diuretics & 1597 & 60.3 \\
\hline$\beta$-blockers & 1426 & 53.8 \\
\hline ACEIs/ARBs & 1438 & 54.3 \\
\hline $\begin{array}{l}\text { Calcium channel blockers and other } \\
\text { antihypertensives }\end{array}$ & 710 & 26.8 \\
\hline Statins & 760 & 28.7 \\
\hline Antiplatelet drugs & 1024 & 38.6 \\
\hline Vitamin $\mathrm{K}$ antagonists & 660 & 24.9 \\
\hline \multicolumn{3}{|l|}{ Number of previous medications } \\
\hline 0 & 264 & 10.0 \\
\hline 1 & 205 & 7.7 \\
\hline 2 & 318 & 12.0 \\
\hline 3 & 471 & 17.8 \\
\hline 4 & 519 & 19.6 \\
\hline 5 & 418 & 15.8 \\
\hline 6 & 275 & 10.4 \\
\hline$\geq 7$ & 180 & 6.8 \\
\hline $\begin{array}{l}\text { Patients with cardiology visit during } \\
\text { follow-up }\end{array}$ & 635 & 24.0 \\
\hline Patients with home care & 1279 & 48.3 \\
\hline Patients included in the HF care pathway & 232 & 8.8 \\
\hline Patients in RCFE & 191 & 7.2 \\
\hline
\end{tabular}

ACEls/ARBs, ACE inhibitors/angiotensin receptor blockers; COPD, chronic obstructive pulmonary disease; HF, heart failure; $\mathrm{PCl}$, percutaneous coronary intervention; RCFE, residential care facility for the elderly.

facilities during the follow-up period-of these, $60.2 \%$ had accessed RCFE prior to the index hospitalisation.

As a whole, $887(33.5 \%)$ patients received none of the outpatient care services described above, while $93(3.5 \%)$ patients were enrolled in the HF care pathway and seen by a cardiologist during follow-up.

\section{Adherence to medication}

Adherence to evidence-based medications after discharge was calculated for patients with an observation period of at least 3 months and with less than $30 \%$ of follow-up spent in the hospital $(n=2243)$. The percentages of adherence to ACEIs/ARBs, $\beta$-blockers and aldosterone antagonists were $46.5 \%, 59.4 \%$ and $35.6 \%$, respectively. 
Table 2 Effect of healthcare factors on adherence to secondary prevention medications in the 3-month to 6-month follow-up period

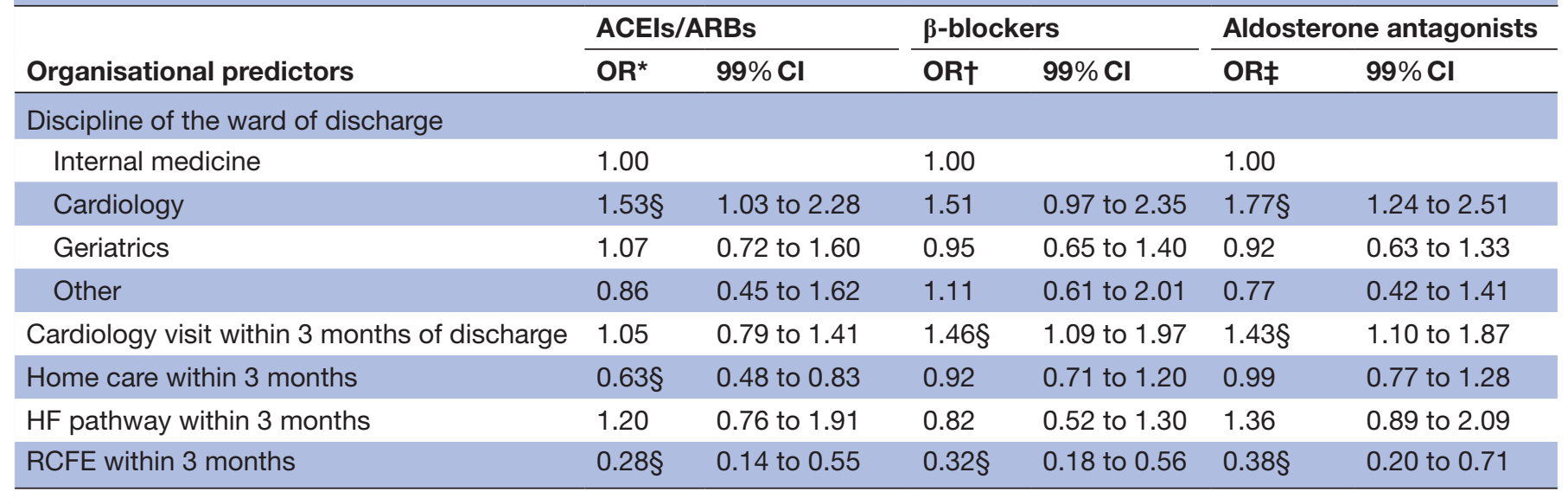

*Adjusted for age, length of stay, chronic nephropathies and previous use of ACEls/ARBs.

${ }^{\dagger}$ Adjusted for age, conduction disorders and cardiac dysrhythmias, previous percutaneous coronary intervention, other surgery of the heart, provision of intensive care during hospital stay and previous use of $\beta$-blockers.

${ }^{\ddagger}$ Adjusted for length of stay, cardiomyopathies, chronic nephropathies and previous use of diuretics.

\$OR significant at the 0.01 level.

ACEIs/ARBs, ACE inhibitors/angiotensin receptor blockers; HF, heart failure; RCFE, residential care facility for the elderly.

There were $705(31.4 \%)$ patients who were adherent to both ACEIs/ARBs and $\beta$-blockers, while there were 310 $(13.8 \%)$ patients with no filled prescriptions of ACEIs/ ARBs and $\beta$-blockers during follow-up (MPR=0\%).

The effect of healthcare factors on adherence to each drug therapy is shown in table 2 . After adjusting for significant patient characteristics, we found that, compared with patients discharged from an internal medicine ward, those discharged from a cardiology ward had an increased likelihood of adherence to ACEIs/ARBs (OR 1.53, 99\% CI 1.30 to 2.28); similarly, patients seen by a cardiologist within 3 months of hospital discharge were more likely to be adherent to $\beta$-blockers (OR 1.46, 99\% CI 1.09 to $1.97)$. Adherence to aldosterone antagonists was favourably influenced by inpatient and outpatient cardiologist care (discharge from cardiology: OR 1.77, 99\% CI 1.24 to 2.51; follow-up visit: OR $1.43,99 \%$ CI 1.10 to 1.87 ). On the contrary, home care and RCFE were associated with a reduction in adherence. Lastly, no association was found between medication adherence and inclusion in the HF care pathway, although a secondary analysis revealed that patients enrolled in this pathway were more likely to be seen by a cardiologist during follow-up (OR 1.67, 99\% CI 1.10 to 2.52 ).

\section{Mortality and readmission}

Mortality and readmission rates at 1,3 and 6 months are shown in figure 1. At the end of follow-up, about one-half of patients $(51.3 \%)$ experienced hospital readmission or visited the ER, while about one-fifth $(21.1 \%)$ died from any cause. Of all readmissions, $39.8 \%$ were HF-related.

The effect of medication adherence and healthcare factors on mortality and readmission is presented in tables 3 and 4. After adjusting for potential confounders, the risk of 6-month mortality was 53\% lower among patients adherent to ACEIs/ARBs and 28\% lower among patients adherent to $\beta$-blockers; a significant mortality reduction associated with adherence to ACEIs/ARBs and $\beta$-blockers was also observed at 1 and 3 months after discharge (table 3). Adherence to ACEIs/ARBs was also associated with a 22\% reduction in readmission rates at 6 months, while adherence to $\beta$-blockers failed to achieve statistical significance (table 4). Adherence to aldosterone antagonists was unrelated to both mortality and readmission.

We also found that home care was associated with a higher mortality risk at 6 months (table 3) and with a higher risk of readmission at 1,3 and 6 months after discharge (table 4). As in the medication adherence analysis, no evidence of association between outcomes and inclusion in the HF care pathway was found.

\section{DISCUSSION}

The main result of this observational study is that patients with HF managed by cardiologists in inpatient and outpatient settings are more adherent to evidencebased medications compared with patients managed by other specialists. In addition, medication adherence to ACEIs/ARBs and $\beta$-blockers was associated with reduced mortality after discharge, and adherence to ACEIs/ARBs was also associated with lower readmission rates.

Our results are consistent with earlier studies that highlighted the influence of cardiologist care on evidencebased treatment adherence, ${ }^{6-101320}$ and in contrast with other studies reporting a direct association of cardiologist care with mortality and readmissions. ${ }^{467-11}$ It is worth noticing that in our study the influence of cardiologist care on mortality and readmission may be explained by adherence to evidence-based medications. 


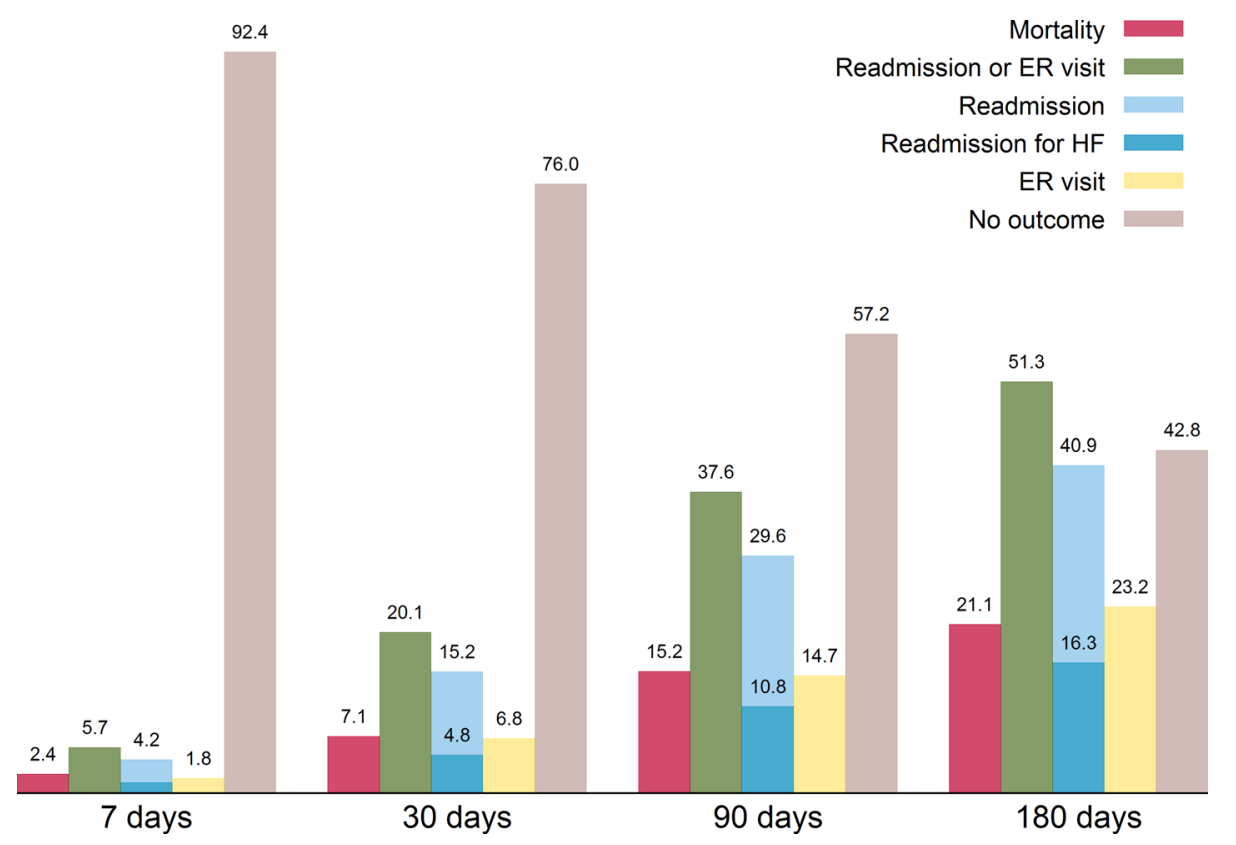

Figure 1 Mortality and readmission rates (\%) at 7, 30, 90 and 180 days after discharge. ER, emergency room; HF, heart failure.

The reason for the favourable impact of cardiologist care on medication adherence might be that cardiologists are particularly skilled in decision making about medication dosing and titration, and are generally more likely to adhere to guideline recommendations. Some authors have also suggested that patients seen by cardiologists are younger, have more cardiovascular comorbidities than other diseases and are therefore at lower risk of contraindications or intolerance to treatments. ${ }^{48101315}$ However, in our study the association between medication adherence and cardiologist care cannot be explained by differences in case mix because our regression analyses were adjusted for many potential confounders (ie, age, gender, comorbidities and length of stay in the index hospitalisation as a proxy of complexity).

Of note, consistent with other studies, ${ }^{32-25}$ we found that medication adherence improved patient mortality. In addition, we found that adherence to ACEIs/ARBs was associated with a reduction in readmission rates at 3 and 6 months, despite the general difficulty of identifying factors affecting hospital readmissions. ${ }^{26-29}$ The predictive power of risk-adjustment models for readmissions after HF has indeed been shown to be scanty and generally lower than the predictive power of mortality models, suggesting that

Table 3 Effect of healthcare factors and medication adherence on mortality at 1, 3 and 6 months after discharge

\begin{tabular}{|c|c|c|c|c|c|c|}
\hline \multirow{2}{*}{$\begin{array}{l}\text { Organisational factors and } \\
\text { medication adherence }\end{array}$} & \multicolumn{2}{|c|}{1 month } & \multicolumn{2}{|c|}{3 months } & \multicolumn{2}{|c|}{6 months } \\
\hline & OR $^{*}$ & $99 \% \mathrm{Cl}$ & OR $^{*}$ & $99 \% \mathrm{Cl}$ & OR $^{*}$ & $99 \% \mathrm{Cl}$ \\
\hline \multicolumn{7}{|c|}{ Discipline of the ward of discharge } \\
\hline Cardiology & 1.39 & 0.61 to 3.19 & 1.16 & 0.68 to 1.98 & 0.92 & 0.58 to 1.49 \\
\hline Geriatrics & 1.59 & 0.93 to 2.73 & 1.28 & 0.89 to 1.84 & 1.34 & 0.98 to 1.82 \\
\hline Cardiology visit & 0.60 & 0.12 to 3.01 & 0.57 & 0.32 to 1.04 & 0.83 & 0.56 to 1.22 \\
\hline Home care & 0.97 & 0.62 to 1.51 & 1.13 & 0.83 to 1.53 & $1.40 \dagger$ & 1.08 to 1.82 \\
\hline HF care pathway & 0.99 & 0.41 to 2.41 & 1.20 & 0.72 to 2.02 & 1.26 & 0.83 to 1.92 \\
\hline RCFE & 1.56 & 0.79 to 3.08 & 1.43 & 0.87 to 2.37 & $1.55 \dagger$ & 1.02 to 2.34 \\
\hline Aldosterone antagonists & 0.84 & 0.48 to 1.48 & 0.95 & 0.68 to 1.34 & 0.94 & 0.71 to 1.24 \\
\hline
\end{tabular}

${ }^{*}$ Adjusted for length of stay, malignant tumours, previous HF, and previous use of $\beta$-blockers and diuretics.

${ }^{\dagger}$ OR significant at the 0.01 level.

ACEIs/ARBs, ACE inhibitors/angiotensin receptor blockers; HF, heart failure; RCFE, residential care facility for the elderly. 
Table 4 Effect of healthcare factors and medication adherence on readmissions (including ER visits) at 1, 3 and 6 months after discharge

\begin{tabular}{|c|c|c|c|c|c|c|}
\hline \multirow{2}{*}{$\begin{array}{l}\text { Organisational factors and } \\
\text { medication adherence }\end{array}$} & \multicolumn{2}{|c|}{1 month } & \multicolumn{2}{|c|}{3 months } & \multicolumn{2}{|c|}{6 months } \\
\hline & $\mathbf{O R}^{*}$ & $99 \% \mathrm{Cl}$ & $\mathrm{OR}^{*}$ & $99 \% \mathrm{Cl}$ & OR $^{*}$ & $99 \% \mathrm{Cl}$ \\
\hline \multicolumn{7}{|c|}{ Discipline of the ward of discharge } \\
\hline Internal medicine & 1.00 & & 1.00 & & 1.00 & \\
\hline Cardiology & 0.96 & 0.65 to 1.41 & 0.93 & 0.70 to 1.24 & 0.88 & 0.69 to 1.13 \\
\hline Geriatrics & 1.08 & 0.77 to 1.52 & 1.08 & 0.84 to 1.39 & 1.13 & 0.91 to 1.40 \\
\hline Other & 1.31 & 0.78 to 2.20 & 1.15 & 0.77 to 1.72 & 1.14 & 0.81 to 1.62 \\
\hline Home care & $1.29 \dagger$ & 1.00 to 1.66 & $1.35 \dagger$ & 1.12 to 1.63 & $1.35 \dagger$ & 1.15 to 1.58 \\
\hline HF care pathway & 1.28 & 0.83 to 1.97 & 1.09 & 0.79 to 1.51 & 1.05 & 0.79 to 1.39 \\
\hline Cardiology visit & 1.00 & 0.59 to 1.72 & 1.08 & 0.81 to 1.43 & 1.15 & 0.93 to 1.43 \\
\hline RCFE & 1.61 & 0.98 to 2.65 & $1.59 \dagger$ & 1.10 to 2.31 & 1.32 & 0.95 to 1.84 \\
\hline \multicolumn{7}{|c|}{ Medication adherence after discharge } \\
\hline ACEIs/ARBs & 0.78 & 0.59 to 1.03 & $0.76+$ & 0.63 to 0.93 & $0.78 \dagger$ & 0.66 to 0.92 \\
\hline$\beta$-blockers & 1.08 & 0.83 to 1.41 & 1.08 & 0.90 to 1.31 & 1.03 & 0.88 to 1.21 \\
\hline Aldosterone antagonists & 0.98 & 0.74 to 1.31 & 0.92 & 0.75 to 1.12 & 0.93 & 0.79 to 1.10 \\
\hline
\end{tabular}

*Adjusted for 'other cardiac diseases', previous percutaneous coronary intervention and previous HF.

${ }^{\dagger}$ OR significant at the 0.01 level.

ACEIs/ARBs, ACE inhibitors/angiotensin receptor blockers; ER, emergency room; HF, heart failure; RCFE, residential care facility for the elderly.

the determinants of readmissions are difficult to be identified and recorded. ${ }^{30}$ Readmissions might depend on the quality of hospital management and, of note, also on the implementation and the quality of organisational models of care in the early postdischarge period. ${ }^{31-34}$ Earlier literature suggests that a coordinated approach to develop a seamless and effective transition between hospital and home is essential to promote the integration between inpatient and outpatient services and to prevent readmissions for patients with chronic diseases as well as HF. ${ }^{35-39}$ In particular, the days immediately following discharge are critical because of the addition of new therapies or changes to existing medical therapy that may deteriorate patients' clinical status outside of the highly structured hospital setting. ${ }^{40}$ In line with other studies, ${ }^{23} 4142$ we found that patients with cardiology visits after discharge were more adherent to evidence-based medications, suggesting that these care services improve outcomes and should be offered routinely to patients with HF.

Our findings also suggest that home care was negatively associated with adherence to ACEIs/ARBs, mortality and readmission. A possible explanation is that patients managed in home-based services are more often characterised by social complexity, that is, tend to live alone without family support or have poor economic conditions that we could not evaluate in our risk-adjustment models.

Concerning the HF care pathway, it had no significant impact on patient outcomes. It may be possible that in the catchment area of the LHA of Bologna, this pathway still has a weak or heterogeneous implementation especially in terms of communication between different physicians (including cardiologists), engagement of patients and caregivers in their pathway of care, follow-up plans, and monitoring of clinical conditions. However, because our databases lack information on specific interventions provided to individual patients enrolled in the HF care pathway, this result should be interpreted with caution and deserve further investigation.

To sum up, our results point out that in any setting of care, the management of drug therapies should be considered as a key element for patients with HF, and should be not only a prerogative of cardiologists but also an essential component of non-specialty models of care. Joynt $e t a t^{33}$ found that clinician expertise may play an important role in HF care, and that high-volume and experienced physicians (including cardiologists) achieved better outcomes when compared with physicians with less experience on HF treatment. Consistent with other research, ${ }^{3}{ }^{16-18}$ our study suggests that, in essence, cardiologists should play an important role in the organisational models tailored to patients with HF, and that both early physician involvement and collaborative approach between specialists and non-specialists might lead to an improved care quality.

Results of the present study should be interpreted in light of some strengths and limitations. Methodological strengths include the study design for the mortality and readmission analyses, in which cases and controls were matched by follow-up duration, thereby preventing time-related bias. ${ }^{44}$ Second, adherence to medication was derived using the 'minimum effective doses' of clinical trials instead of the more commonly used 'defined daily doses', which are generally higher than what is actually prescribed for secondary prevention after HF. Third, we mapped healthcare use of each individual patient, thanks 
to the possibility to link different administrative data sources using the patient's unique identifier.

Limitations include, first, the absence of lifestyle behaviours (eg, diet, physical activity), socioeconomic factors (eg, education level, income) and relevant clinical information (eg, body mass index, left ventricular ejection fraction) in the HDR Database. Although analyses were adjusted for many factors including comorbid conditions and previous use of drug therapies, it is possible that the lack of more detailed data has left room for some residual confounding. However, when we reran all regression analyses by including serum creatinine at hospital admission $(\mathrm{n}=2187)$, which in a previous study has been shown to be strongly associated with short-term mortality following $\mathrm{HF}^{45}$ results did not change appreciably (data not presented). Second, adherence was estimated using pharmacy data on filled prescriptions, but no information on actual medication consumption was available. Moreover, the adherence cut-off point of $75 \%$ was defined a priori and not in a data-driven way. To address this limitation, we carried out sensitivity analyses using different cut-off points (50\%-90\%) and alternative adherence measures (ie, pill count and proportion of days covered), and results were unchanged (data not presented). The last limitation is the potential lack of generalisability to other settings; however, this study included all patients with HF from one of the largest Italian LHAs and it is likely that our findings would be generalisable to other regions or countries with a population composition and healthcare delivery system similar to those of this study.

In conclusion, the results of the present study suggest that policy makers and healthcare organisation managers should reconsider the role of cardiologists in the management of patients with HF. Cardiologists can be involved not necessarily as main professionals, but also as consultants to plan and monitor pharmacological treatment during the hospital stay and early postdischarge period. Further research is needed to evaluate in more detail which are the key elements of the specialty and non-specialty management of HF that influence patient outcomes and to identify for what type of patients or in which setting cardiologists provide the greatest value.

\footnotetext{
Author affiliations

${ }^{1}$ Department of Biomedical and Neuromotor Sciences, Alma Mater Studiorum University of Bologna, Bologna, Emilia-Romagna, Italy

${ }^{2}$ Department of Cardiology, Bellaria Hospital, Bologna, Emilia-Romagna, Italy ${ }^{3}$ Department of Management Control and Administrative Data, Bologna Local Healthcare Authority, Bologna, Emilia-Romagna, Italy

${ }^{4}$ Department of Clinical Governance and Quality, Bologna Local Healthcare Authority, Bologna, Emilia-Romagna, Italy

${ }^{5}$ Regional Agency for Health and Social Care of Emilia-Romagna, Bologna, EmiliaRomagna, Italy

${ }^{6}$ Department of Clinical Governance and Quality, St Orsola-Malpighi Hospital, Bologna, Emilia-Romagna, Italy

${ }^{7}$ Medical Directorate, Bologna Local Healthcare Authority, Bologna, Emilia-Romagna, Italy
}

Acknowledgements The authors thank Laura Lama, MD, and Claudio Rapezzi, MD, from the Bologna St Orsola-Malpighi Polyclinic, Rossella D'Avenia, MD, from the University of Bologna, and Maria Cristina Pirazzini, MS, from the Bologna Local Healthcare Authority for their assistance in interpretation of data.

Contributors VMA, JL and MPF made substantial contributions to the conception and design, analysis and interpretation of data, drafted the manuscript and revised it critically for important content, and approved final version to be published. DM was responsible for data collection, revised the article critically for important intellectual content and approved the final version to be published. SU, CD, AC, MT and AF were responsible for interpretation of data, revised the article critically for important intellectual content and approved the final version to be published. MPF is a guarantor of the study.

Funding This research received no grant from any funding agency in the public, commercial or not-for-profit sectors.

Competing interests None declared.

Patient consent Detail has been removed from this case description/these case descriptions to ensure anonymity. The editors and reviewers have seen the detailed information available and are satisfied that the information backs up the case the authors are making.

Ethics approval The study was exempt from notification to the Ethics Committee of the LHA of Bologna. It was conducted in conformity with the regulations for data management from the Regional Health Authority of Emilia-Romagna, and with the Italian Code of conduct and professional practice applying to processing of personal data for statistical and scientific purposes (art 20-21, legislative decree 196/2003;) published in the Official Journal No 190 of 14 August 2004, which explicitly exempts the need for approval from the Ethics Committee when using anonymous data (preamble number 8).

Provenance and peer review Not commissioned; externally peer reviewed.

Data sharing statement Statistical code and raw data are available by emailing jacopo.lenzi2@unibo.it.

Open Access This is an Open Access article distributed in accordance with the Creative Commons Attribution Non Commercial (CC BY-NC 4.0) license, which permits others to distribute, remix, adapt, build upon this work non-commercially, and license their derivative works on different terms, provided the original work is properly cited and the use is non-commercial. See: http://creativecommons.org/ licenses/by-nc/4.0/

(c) Article author(s) (or their employer(s) unless otherwise stated in the text of the article) 2017. All rights reserved. No commercial use is permitted unless otherwise expressly granted.

\section{REFERENCES}

1. Mosterd A, Hoes AW. Clinical epidemiology of heart failure. Heart 2007;93:1137-46.

2. Dunlay SM, Roger VL. Understanding the epidemic of heart failure: past, present, and future. Curr Heart Fail Rep 2014;11:404-15.

3. Ponikowski P, Voors AA, Anker SD, et al. 2016 ESC Guidelines for the diagnosis and treatment of acute and chronic heart failure: The Task Force for the diagnosis and treatment of acute and chronic heart failure of the European Society of Cardiology (ESC)Developed with the special contribution of the Heart Failure Association (HFA) of the ESC. Eur Heart J 2016;37:2129-200.

4. Auerbach AD. Resource Use and survival of patients hospitalized with congestive Heart failure: differences in care by specialty of the attending physician. Ann Intern Med 2000;132:191-200.

5. Grigioni F, Carinci V, Favero L, et al. Hospitalization for congestive heart failure: is it still a cardiology business? Eur J Heart Fail 2002;4:99-104.

6. Jong P, Gong Y, Liu PP, et al. Care and outcomes of patients newly hospitalized for heart failure in the community treated by cardiologists compared with other specialists. Circulation 2003;108:184-91.

7. Foody JM, Rathore SS, Wang Y, et al. Physician specialty and mortality among elderly patients hospitalized with heart failure. Am J Med 2005;118:1120-5.

8. Boom NK, Lee DS, Tu JV. Comparison of processes of care and clinical outcomes for patients newly hospitalized for heart failure attended by different physician specialists. Am Heart $J$ 2012;163:252-9.

9. Parmar KR, Xiu PY, Chowdhury MR, et al. In-hospital treatment and outcomes of heart failure in specialist and non-specialist services: a retrospective cohort study in the elderly. Open Heart 2015;2:e000095. 
10. Selim AM, Mazurek JA, lqbal M, et al. Mortality and readmission rates in patients hospitalized for acute decompensated heart failure: a comparison between cardiology and general-medicine service outcomes in an underserved population. Clin Cardiol 2015;38:131-8.

11. Uthamalingam S, Kandala J, Selvaraj V, et al. Outcomes of patients with acute decompensated heart failure managed by cardiologists versus noncardiologists. Am J Cardiol 2015;115:466-71.

12. Philbin EF, Jenkins PL. Differences between patients with heart failure treated by cardiologists, internists, family physicians, and other physicians: analysis of a large, statewide database. Am Heart $J$ 2000;139:491-6.

13. Bellotti P, Badano LP, Acquarone N, et al. Specialty-related differences in the epidemiology, clinical profile, management and outcome of patients hospitalized for heart failure; the OSCUR study. Oucome dello scompenso cardiaco in relazione all'Utilizzo delle Risore. Eur Heart J 2001;22:596-604.

14. Di Lenarda A, Scherillo M, Maggioni AP, et al. Current presentation and management of heart failure in cardiology and internal medicine hospital units: a tale of two worlds--the TEMISTOCLE study. Am Heart J 2003;146:735.

15. Lowe J, Candlish P, Henry D, et al. Specialist or generalist care? A study of the impact of a selective admitting policy for patients with cardiac failure. Int J Qual Health Care 2000;12:339-45.

16. Ahmed A, Allman RM, Kiefe $\mathrm{Cl}$, et al. Association of consultation between generalists and cardiologists with quality and outcomes of heart failure care. Am Heart J 2003;145:1086-93.

17. Indridason OS, Coffman CJ, Oddone EZ. Is specialty care associated with improved survival of patients with congestive heart failure? Am Heart J 2003:145:300-9.

18. Lee DS, Stukel TA, Austin PC, et al. Improved outcomes with early collaborative care of ambulatory heart failure patients discharged from the emergency department. Circulation 2010;122:1806-14.

19. Suissa S. Immeasurable time bias in observational studies of drug effects on mortality. Am J Epidemiol 2008;168:329-35.

20. Ansari M, Alexander M, Tutar A, et al. Cardiology participation improves outcomes in patients with new-onset heart failure in the outpatient setting. J Am Coll Cardiol 2003;41:62-8.

21. Al-Gobari M, El Khatib C, Pillon F, et al. $\beta$-Blockers for the prevention of sudden cardiac death in heart failure patients: a meta-analysis of randomized controlled trials. BMC Cardiovasc Disord 2013;13:52.

22. Sakata $Y$, Nochioka K, Miura M, et al. Supplemental benefit of an angiotensin receptor blocker in hypertensive patients with stable heart failure using olmesartan (SUPPORT) trial--rationale and design. J Cardiol 2013;62:31-6.

23. Yancy CW, Jessup M, Bozkurt B, et al. Correction to: 2016 ACC/ AHA/HFSA focused update on new pharmacological therapy for heart failure: an update of the 2013 ACCF/AHA guideline for the management of heart failure: a report of the american college of cardiology foundation/American heart association task force on clinical practice Guidelines and the heart failure society of America. Circulation 2016;134:e298.

24. Chowdhury R, Khan H, Heydon E, et al. Adherence to cardiovascular therapy: a meta-analysis of prevalence and clinical consequences. Eur Heart J 2013;34:2940-8.

25. Corrao G, Ghirardi A, Ibrahim B, et al. Short- and long-term mortality and hospital readmissions among patients with new hospitalization for heart failure: A population-based investigation from Italy. Int $J$ Cardiol 2015;181:81-7.

26. Vaduganathan M, Fonarow GC, Gheorghiade M. Drug therapy to reduce early readmission risk in heart failure: ready for prime time? JACC Heart Fail 2013;1:361-4.
27. Fischer C, Steyerberg EW, Fonarow GC, et al. A systematic review and meta-analysis on the association between quality of hospital care and readmission rates in patients with heart failure. Am Heart $J$ 2015;170:1005-17.

28. Ziaeian B, Fonarow GC. The prevention of hospital readmissions in heart failure. Prog Cardiovasc Dis 2016;58:379-85.

29. O'Connor CM. High heart failure readmission rates: is it the health system's fault? JACC Heart Fail 2017;5:393.

30. Kansagara D, Englander $\mathrm{H}$, Salanitro $\mathrm{A}$, et al. Risk prediction models for hospital readmission: a systematic review. JAMA 2011;306:1688-98.

31. Rich MW, Beckham V, Wittenberg C, et al. A multidisciplinary intervention to prevent the readmission of elderly patients with congestive heart failure. N Engl J Med 1995;333:1190-5.

32. McAlister FA, Stewart S, Ferrua S, et al. Multidisciplinary strategies for the management of heart failure patients at high risk for admission: a systematic review of randomized trials. J Am Coll Cardiol 2004;44:810-9.

33. Takeda A, Taylor SJ, Taylor RS, et al. Clinical service organisation for heart failure. Cochrane Database Syst Rev 2012;9:CD002752.

34. Garin N, Carballo S, Gerstel E, et al. Inclusion into a heart failure critical pathway reduces the risk of death or readmission after hospital discharge. Eur J Intern Med 2012;23:760-4.

35. Peikes D, Chen A, Schore J, et al. Effects of care coordination on hospitalization, quality of care, and health care expenditures among medicare beneficiaries: 15 randomized trials. JAMA 2009;301:603-18.

36. Driscoll A, Meagher S, Kennedy R, et al. What is the impact of systems of care for heart failure on patients diagnosed with heart failure: a systematic review. BMC Cardiovasc Disord 2016;16:195.

37. Wever-Pinzon O, Drakos SG, Fang JC. Team-based care for advanced heart failure. Heart Fail Clin 2015;11:467-77.

38. Tingley J, Dolansky MA, Walsh MN. Team-based transitions of care in heart failure. Heart Fail Clin 2015;11:371-8.

39. Creaser JW, DePasquale EC, Vandenbogaart E, et al. Teambased care for outpatients with heart failure. Heart Fail Clin 2015;11:379-405.

40. Leendertse AJ, Egberts AC, Stoker LJ, et al. Frequency of and risk factors for preventable medication-related hospital admissions in the Netherlands. Arch Intern Med 2008;168:1890-6.

41. Hernandez AF, Greiner MA, Fonarow GC, et al. Relationship between early physician follow-up and 30-day readmission among Medicare beneficiaries hospitalized for heart failure. JAMA 2010;303:1716-22.

42. Ezekowitz JA, van Walraven C, McAlister FA, et al. Impact of specialist follow-up in outpatients with congestive heart failure. CMAJ 2005;172:189-94.

43. Joynt KE, Orav EJ, Jha AK. Physician volume, specialty, and outcomes of care for patients with heart failure. Circ Heart Fail 2013:6:890-7.

44. Lenzi J, Rucci P, Castaldini I, et al. Does age modify the relationship between adherence to secondary prevention medications and mortality after acute myocardial infarction? A nested case-control study. Eur J Clin Pharmacol 2015;71:243-50.

45. Lenzi J, Avaldi VM, Hernandez-Boussard T, et al. Risk-adjustment models for heart failure patients' 30-day mortality and readmission rates: the incremental value of clinical data abstracted from medical charts beyond hospital discharge record. BMC Health Serv Res 2016;16:473. 